\title{
MULTI-MODE ANALYSIS OF RAYLEIGH-TYPE Lg. PART 2. APPLICATION TO SOUTHERN CALIFORNIA AND THE NORTHWESTERN SIERRA NEVADA
}

\author{
By Michel Cara, * J. Bernard Minster, $†$ and Ronan Le Bras
}

\begin{abstract}
The UC diagram technique described in the companion paper (Part 1), is applied to nine sets of $\mathbf{L g}$ phases recorded through the CEDAR system in southern California, and two sets of $L g$ phases recorded along the northwestern margin of the Sierra Nevada. A clear image of the signal is obtained in timefrequency-wavenumber space, and we discuss in particular observations at 2.5$\mathrm{sec}$ period, for events 200 to $300 \mathrm{~km}$ outside the profiles. From the gross features of UC diagrams we conclude that a representation of $\mathrm{Lg}$ as a single coherent multi-mode wave train is oversimplified in the case of southern California but is more appropriate for the Sierra block. In southern California, peaks observed at group velocities smaller than $3.2 \mathrm{~km} / \mathrm{sec}$ are not predicted by realistic crustal models of the area, and are probably due to lateral heterogeneities effects such as mode conversion and multipathing. On the other hand, for group velocities between 3.2 and $3.6 \mathrm{~km} / \mathrm{sec}$, peaks observed in either area can generally be interpreted in terms of overtones excited at the source and propagating through spatially averaged structures, although care must be taken to monitor the stability of the algorithm on actual short-period records.
\end{abstract}

\section{INTRODUCTION}

We have shown in a companion paper (Cara and Minster, 1981; Part 1) that analysis of short-period vertical seismograms of $L g$ along a $300-\mathrm{km}$ linear array of about 10 stations should allow us to isolate Rayleigh wave overtones in the period range 2 to 5 sec. At epicentral distances of a few hundred kilometers, $L g$ merges with its high-frequency counterpart, usually called $S g$. We shall, however, use the notation $L g$ for the relatively long-period signal under study here, even at a few hundred kilometers from the source. As we shall see, this signal is generally observed at rather low-group velocities $(\sim 3.3 \mathrm{~km} / \mathrm{sec})$ and corresponds to the $L g_{2}$ phase defined by Båth (1956).

Observations of $\mathrm{Lg}$ have long been reported in central and southern California (Gutenberg, 1955; Press, 1956). Press (1956) found a velocity of $3.54 \mathrm{~km} / \mathrm{sec}$ for the first $L g$ arrivals observed in central and southern California, at distances 315 to 870 $\mathrm{km}$. The SCARLET array and the CEDAR digital recording system provide a good opportunity to apply the method described in Part 1 to $L g$ data in southern California (Figure 2b).

For comparison, we shall also analyze $L g$ phases recorded along the northwestern margin of the Sierra Nevada at CALNET stations. In this case, the path lies mainly along the Sierra batholith and is potentially less complicated (Figure 13).

As discussed in Part 1, one of the most stringent implicit assumptions of the method is that the crust is laterally homogeneous. Even in the case of azimuthal homogeneity about the source, crustal changes along the profile can lead to difficulties (e.g., mode conversion, local changes in phase velocity, etc.). The main question dealt with in this paper is whether lateral variations are small enough,

\footnotetext{
* Present address: Institut de Physique du Globe, 5 rue Descartes, 67084 Strasbourg, Cedex, France.
}

$\dagger$ Present address: Systems, Science and Software, Inc, P O. Box 1620, La Jolla, Californa 92038. 
relative to the analytical resolution power of the array, that each overtone appears as an isolated peak on the UC diagram. As we have shown in Part 1, too strong lateral variations broaden the peaks and can even split them into several peaks.

Before turning to a description of our experimental results, we first proceed with an analysis of noise and instrumental limitations on the method for SCARLET. Experimental results which make use of this network are described in "Experimental Results" and "Stability of Observations in Southern California," and further results which make use of CALNET stations are presented in "Further Experimental Results."

\section{Instrumental and Noise Constraints for CEDAR Data}

The SCARLET network comprises over 150 short-period vertical seismic stations in southern California (e.g., Hutton et al., 1979). This network is monitored through the CEDAR digital recording system (Johnson, 1979). Both network and recording systems are designed for optimal detection, recording, and routine processing of small local earthquakes. Thus, despite the obvious advantages of processing digital data through a stacking algorithm, we are faced with serious limitations when looking at late arrivals such as $L g$, for sources outside the network.

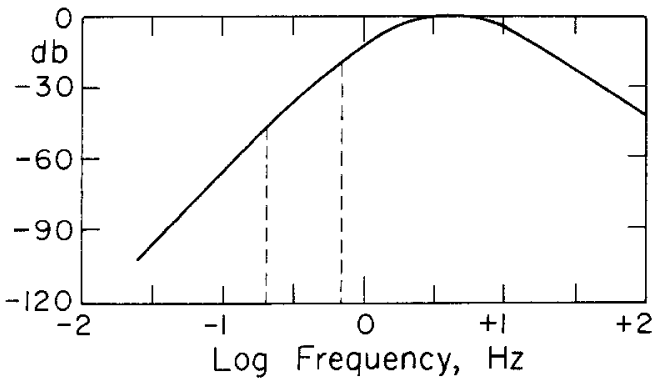

FIG. 1. Magnification curve of a typical SCARLET/CEDAR seismographic system (station + telemetry + recordung system). Period range of interest $\mathrm{m}$ this study is shown by dashed lines ( 15 to 5 sec).

Due to these constraints, usable $L g$ phases from routinely archived data are generally limited to events at epicentral distances 200 to $700 \mathrm{~km}$ and with local magnitudes $M_{L} \sim 4.0$ to 4.4. Signals from larger events are often clipped on too many stations at these distances, and routine recordings of farther events are usually too short to include $L g$ at all but the nearest stations. We report here on observations for these distance and magnitude ranges. Most sources used in this study are earthquakes located in the Sierra Nevada-Owens Valley seismic area near Bishop, California (e.g., Hileman et al., 1973; Hutton et al., 1979).

Figure 1 shows a typical magnification curve for the complete seismographic system (station + telemetry + recording system). Although the equipment varies somewhat from station to station, the magnification curve remains much the same in the period range of interest. The effective dynamic range of the system is limited in practice to about $45 \mathrm{~dB}$ by the telephonic FM transmission between field site and the Seismological Laboratory; this is much less than the dynamic range of either the seismometer-amplifier $(\sim 65 \mathrm{~dB})$ or the 12-bit digital recording system. However, as seen from Figure 1, this permits retrieval of information to a period of at least 5 sec if the 0.5 - to 1.0 -sec component is just on scale and saturation does not occur at other frequencies.

To correct for instrumental differences between stations, a frequency domain 
deconvolution was performed through (1) phase correction in the entire frequency range, followed by (2) amplitude deconvolution down to the -45 - $\mathrm{dB}$ level, constant amplitude correction between -45 and $-65 \mathrm{~dB}$ ( $\sim$ periods 5 to $10 \mathrm{sec}$ ), and low-cut filtering beyond that point. We used the theoretical transfer functions reported by Kanamori et al. (1979) and Archambeau (1979). In view of remaining large uncertainties in the actual gains, the deconvolved ground displacement records were normalized to the same amplitude in the group velocity window 3.1 to $3.6 \mathrm{~km} / \mathrm{sec}$.

Seismic noise is particularly important in the period range 2 to $5 \mathrm{sec}$, and thus constitutes an obvious source of complications when applying the UC diagram technique described in Part 1 to CEDAR data at these periods. In order to assess the stability of the algorithm in the presence of noise, we have performed a numerical experiment with a synthetic signal superimposed on natural seismic noise. The experiment simulates $L g$ propagation along profile 1 (Figure $2 \mathrm{~b}$ ) for a fictitious source with the same location as event 1 (Table 1), and the crustal structure derived from the refraction model of Kanamori and Hadley (1975). Details on the crustal structure and on the composition of synthetic $L g$ are found in Part 1 (see, in particular, Figure 2, which corresponds to profile 1).

Seismic noise recorded in January 1980 during a false alarm trigger of the CEDAR system is then added to the synthetic $L g$ phases, with different "signal-to-noise" ( $S$ / $N)$ ratio, and the result processed through the full algorithm. We define here $S / N$ in the time domain as the ratio of synthetic $L g$ amplitude to noise amplitude after deconvolution (maximum peak-to-trough amplitude in the velocity window 3.1 to $3.6 \mathrm{~km} / \mathrm{sec})$.

For pure seismic noise $(S / N=0)$, the 2.5-sec period UC diagram is shown in Figure 3. As could be expected, several peaks appear with rather random locations. These peaks could generate artifacts in the analysis of actual data. It is unfortunately impossible to identify them as noise rather than signal if no a priori knowledge of overtone peaks is available from independent geophysical information.

Figure 4 shows the profile of synthetic $L g$ plus natural noise, for $S / N=2$. The corresponding UC diagram at $2.5 \mathrm{sec}$ is given on Figure 5. It is very encouraging that the observed peaks remain so close to their theoretical positions, thus indicating a good stability of the algorithm in the presence of moderate seismic noise. Even with $S / N=0.5$, overtone peaks are still recognizable (Figure 6) but are either strongly attenuated (mode 3 ) or perturbed (mode 2).

Thus, although a high-noise level is a clear source of difficulties, we may conclude that the method is applicable at low to moderate noise levels. A practical criterion is that the noise amplitude be low at earlier times (i.e., greater group velocities) than $\mathrm{Lg}$ arrivals for the period considered. For example, it is less than 20 per cent on the UC diagram shown on Figure 5, and nearly 50 per cent on Figure 6.

\section{Experimental Results: Southern California}

Proposed models of crustal structure show a surprising degree of lateral homogeneity over wide areas of southern California. From refraction data, Kanamori and Hadley (1975) found no significant difference between the upper crust of the western Mojave desert, the central and eastern Transverse Ranges, and the northern Peninsular Ranges (Figure 2a). The deeper crust is not so well constrained in their study, but Moho reflections and an estimate of the $P_{n}$ critical distance led the authors to fix Moho depth between 30 and $35 \mathrm{~km}$. In a further study, Hadley and Kanamori (1979) concluded that the model is consistent with fundamental Rayleigh mode data if Poisson's ratio is about 0.25 in the crust. Moreover, the latter study 

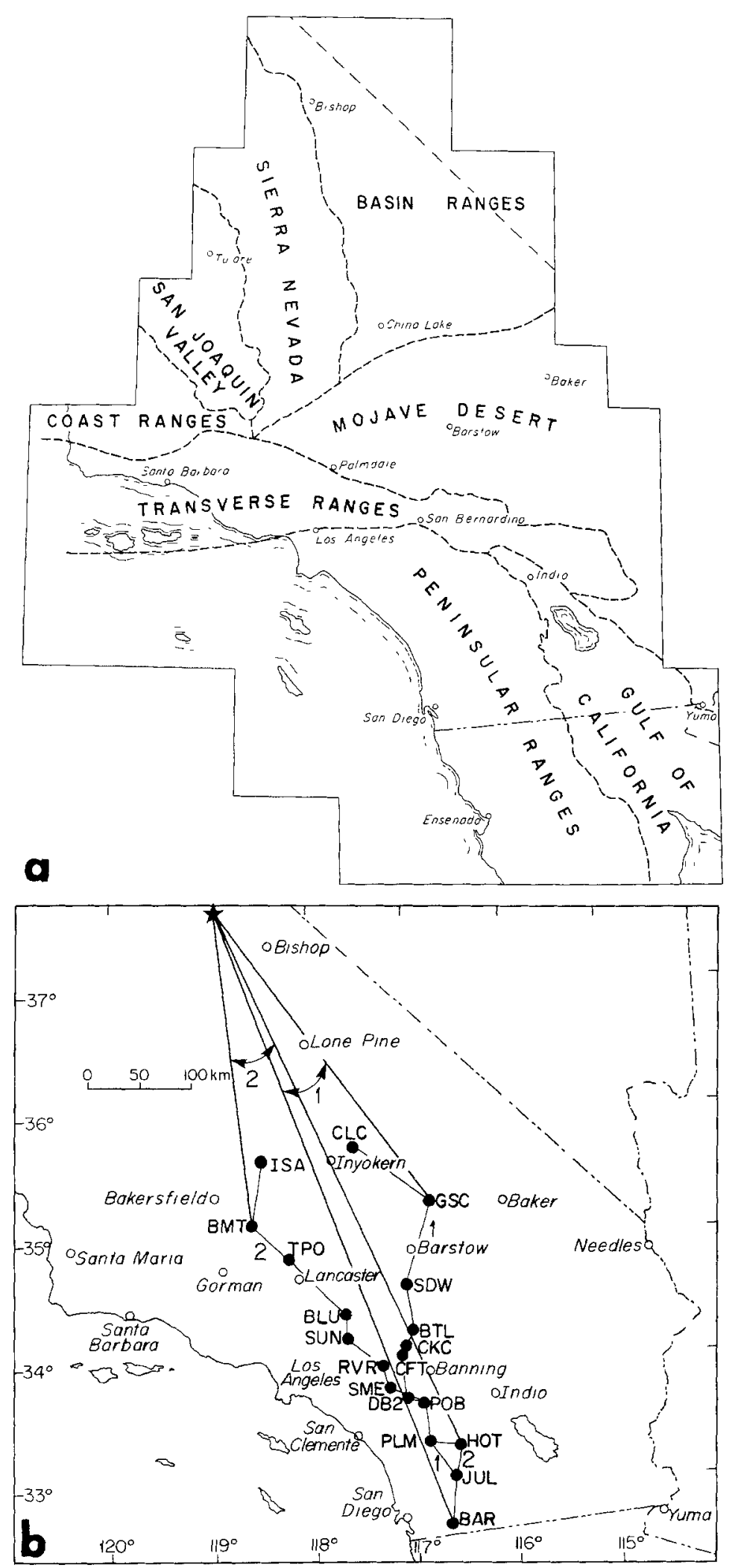

Fig. 2. Southern California tectonic regions (a) (after Allen et al., 1965) and locations of two profiles of SCARLET/CEDAR stations used as example in this study (b), for event 1 (Table 1). Arrows indicate the maximum range in azimuth of profiles 1 and 2 . 
has also shown that a similar $S$-velocity structure can account for Rayleigh wave dispersion in the Peninsular Ranges, Poisson's ratio being somewhat larger $(\sim 0.28)$ in that case.

Direct calculation of Rayleigh wave overtone phase velocity in the period range 2 to 5 sec yields essentially the same results for the two models proposed by Hadley and Kanamori (1979). Thus, although strong E-W lateral variations exist in the Peninsular Ranges (Hadley and Kanamori, 1979), it seems that no drastic change in

TABLE 1

List of Events Near Bishop, California, Used in This Study Source Parameters Are from Caltech-USGS Monthly Preliminary Epicenters Catalog

\begin{tabular}{|c|c|c|c|c|c|c|}
\hline Event & Date & $H_{0}$ & Lat $(\mathrm{N})$ & Long (W) & $h(\mathrm{~km})$ & $M$ \\
\hline 2 & 9 November 1979 & $17 \mathrm{~h} 54 \mathrm{~m} 16.0 \mathrm{~s}$ & $37^{\circ} 36.14$ & $118^{\circ} 57.16$ & 60 & 4.4 \\
\hline 4 & 4 October 1979 & $17 \mathrm{~h} 46 \mathrm{~m} 47.5 \mathrm{~s}$ & $37^{\circ} 32.20$ & $118^{\circ} 3660$ & 7.5 & 4.3 \\
\hline 5 & 7 September 1979 & $9 \mathrm{~h} 43 \mathrm{~m} 484 \mathrm{~s}$ & $37^{\circ} 3816$ & $118^{\circ} 5495$ & 35 & 4.4 \\
\hline 7 & 24 September 1979 & $14 \mathrm{~h} 26 \mathrm{~m} 20.6 \mathrm{~s}$ & $37^{\circ} 41.02$ & $118^{\circ} 47.40$ & 5.0 & 4.0 \\
\hline
\end{tabular}

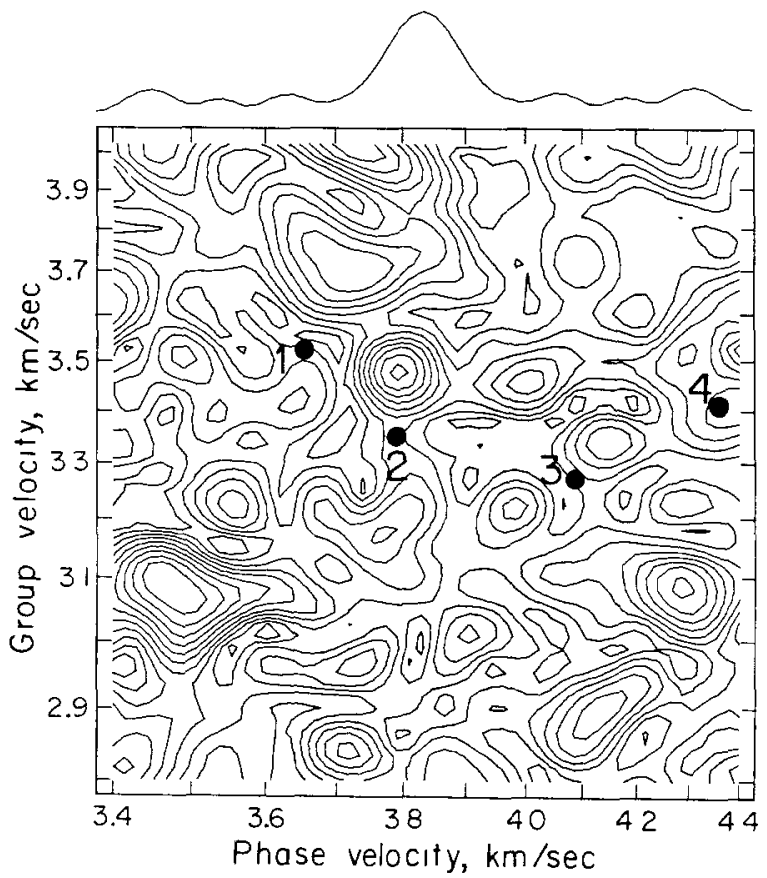

Fig 3. UC diagram (see Part 1) at 2.5-sec period of pure seismic noise records Solid dots show the location of theoretical UC coordinates predicted by the model derived in Part 1 from Kanamorn and Hadley (1975). (Also see Table 2.) Contour spacing = 10 per cent of the maximum amplitude.

overtone dispersion is expected a priori along N-S profiles running through western Mojave desert, the central Transverse and the Peninsular Ranges. For this reason, we chose profiles similar to those displayed on Figure $2 \mathrm{~b}$ for an initial experimental study. A typical section for event 1 (Table 1) recorded along profile 2 (Figure $2 b$ ) is displayed on Figure 7, and after deconvolution, on Figure 8. Since the traces have been normalized to have the same amplitude in the group velocity window 3.1 to 3.6 


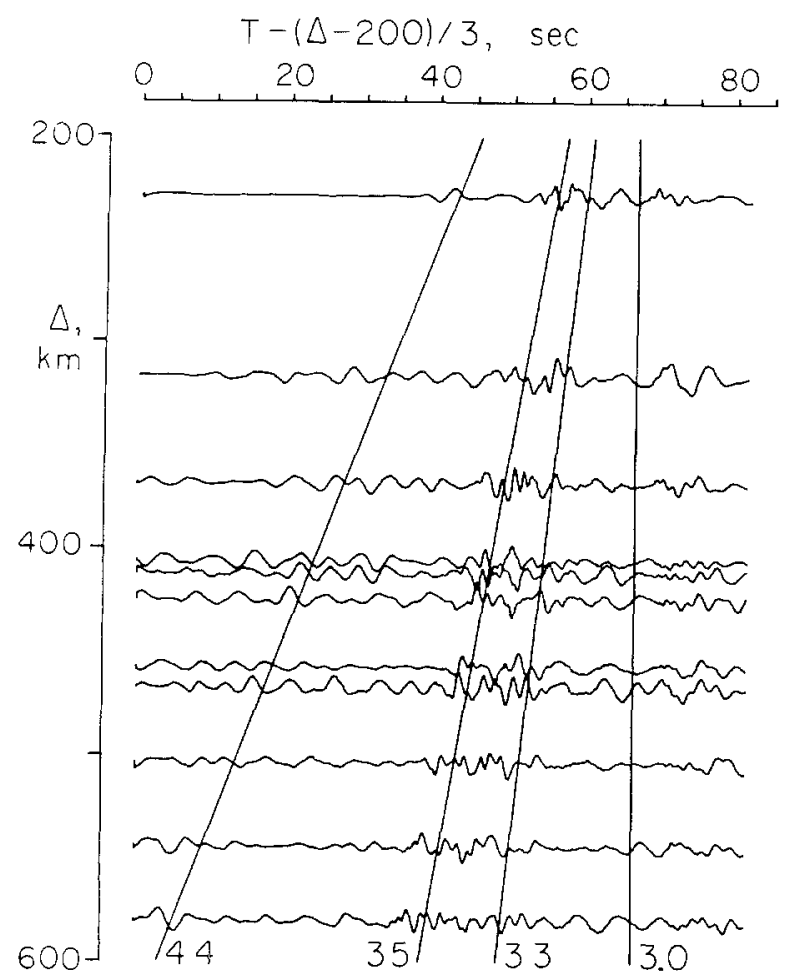

Fig 4 Synthetic $L g$ plus noise records $(S / N=2)$ after deconvolution

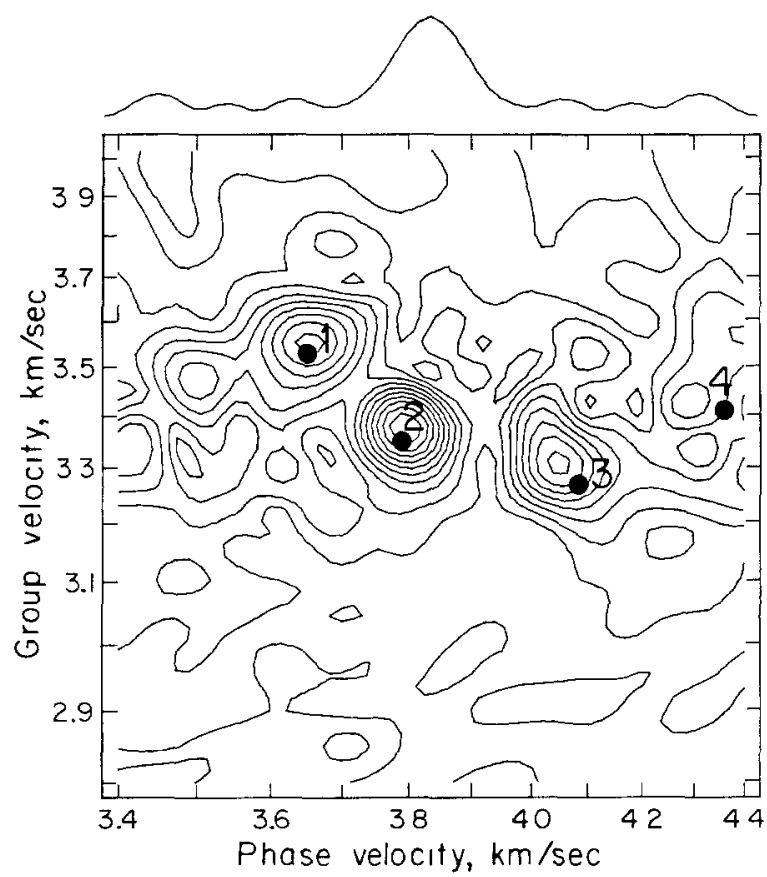

Fig 5. UC diagrams obtained by stacking the records shown in Figure 4. See caption for Figure 3. 


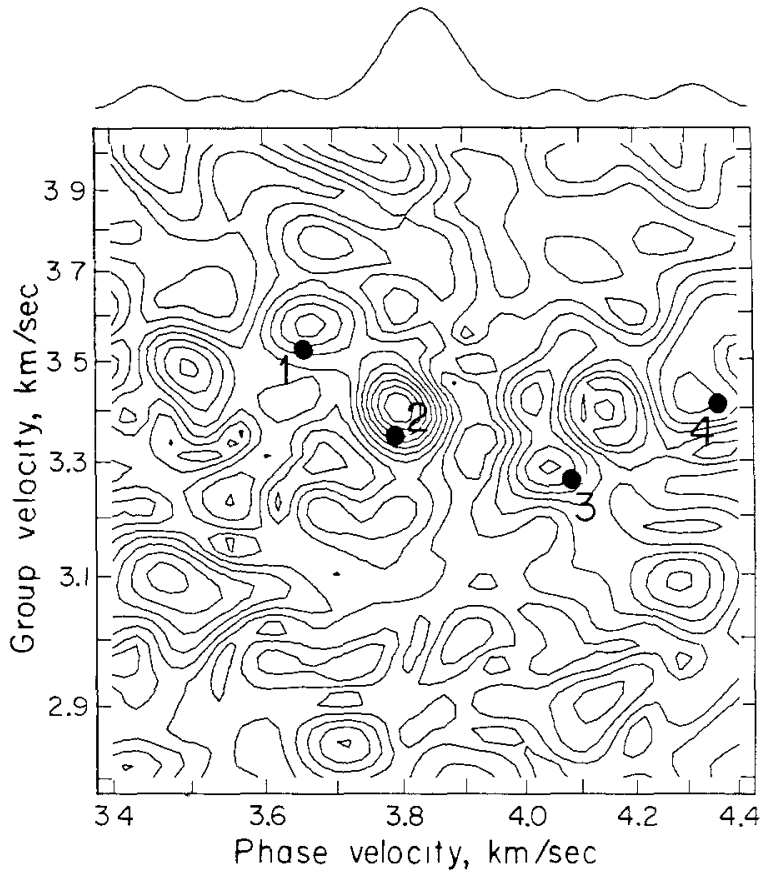

Fig. 6. UC diagram as in Figure 5 but for $S / N=05$

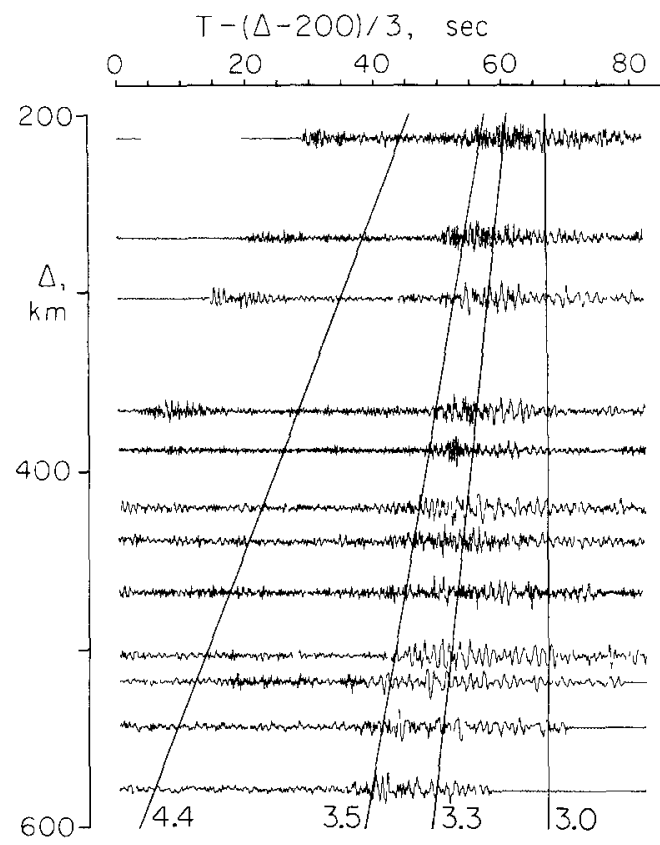

FIG 7 Example of vertical component records, including $L g$, on profile 2 from SCARLET/CEDAR system after low-pass filtering (flat response for frequencies smaller than $0.5 \mathrm{~Hz}$, and linear decrease to zero between 0.5 and $2 \mathrm{~Hz}$ )

$\mathrm{km} / \mathrm{sec}$, noise levels are quite enhanced at the farthest stations on Figure 8. Figure 9 shows the corresponding UC diagram at $2.5 \mathrm{sec}$. This period was chosen for purposes of illustration as a compromise between (1) instrumental constraints which restrict us to periods shorter than $5 \mathrm{sec}$ as discussed earlier, and (2) theoretical 


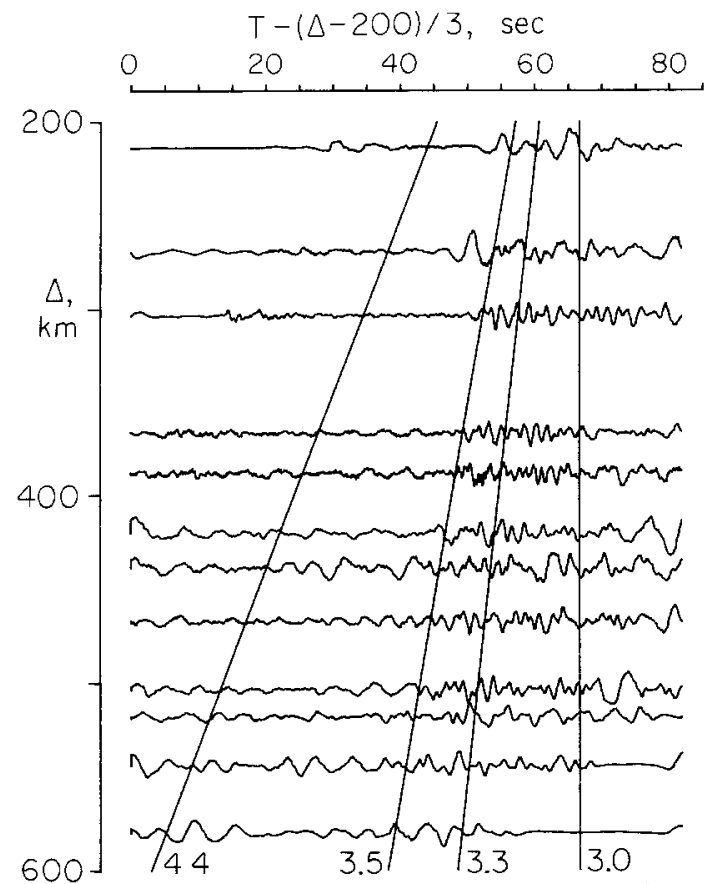

Fig. 8. $L g$ records shown in Figure 7, after deconvolution

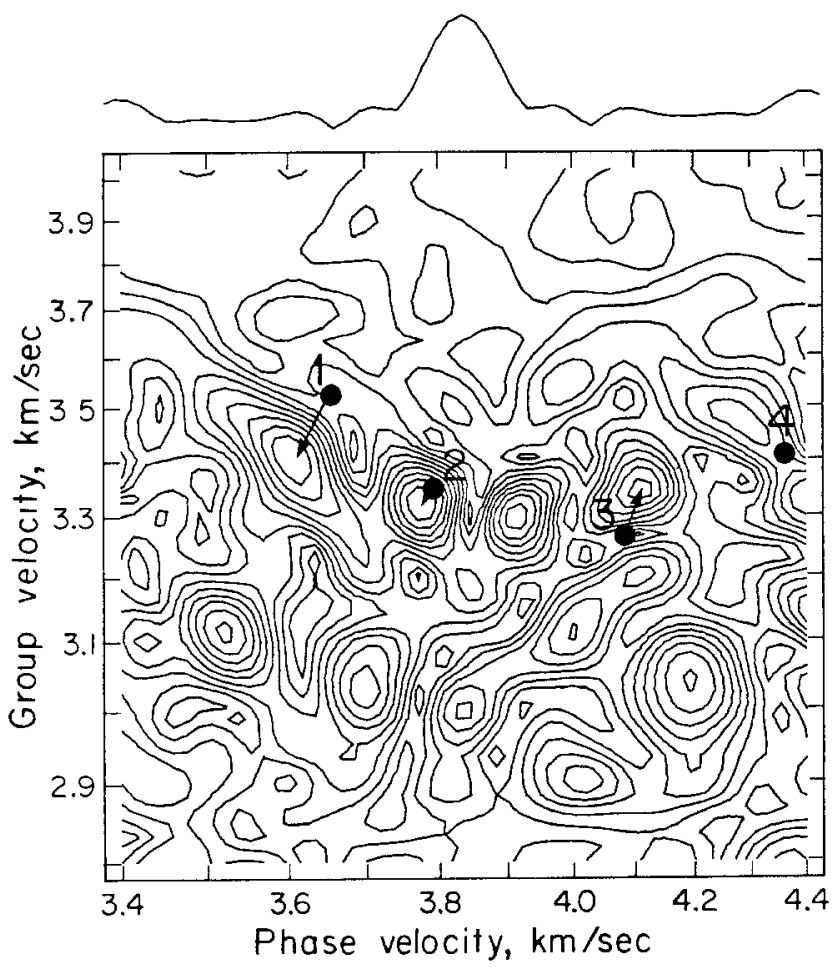

FIG. 9. UC diagram obtained by stacking the records of Figure 8 (profile 2, event 1). See caption for Figure 3 Arrows indicate the peak which is closest to theoretical UC coordmates.

results showing that, at periods shorter than 2 sec, the spacing and position of phase velocity curves are very sensitive to the details of crustal structure. The same event, recorded along profile 1 (Figure $2 b$ ) yields the UC diagram shown in Figure 10.

Figures 9 and 10 exhibit significant differences, particularly in the details of energy 
distribution in the UC plane, but also some fundamental similarities. Compared with the synthetic $L g$ mixed with moderate to strong natural noise shown on Figures 5 and 6 , the present UC diagrams display a significantly different pattern. For synthetic and actual data contour levels are low for group velocities greater than 3.5 $\mathrm{km} / \mathrm{sec}$, but high energy levels persist for group velocities smaller than $3.2 \mathrm{~km} / \mathrm{sec}$ in the case of actual data whereas little late energy is observed on the synthetics. We have found this pattern on all UC diagrams calculated at this period from SCARLET/CEDAR data. This includes an aftershock of the 6 August 1979 central California Coyote Lake earthquake, recorded along a NW-SE profile across the network, and Baja California event (south of the network) recorded along a profile similar to profiles 1 and 2 (Figure $2 \mathrm{~b}$ ). In the latter case, while clear $L g$ arrivals were found on all records (at distances from 660 to $1050 \mathrm{~km}$ ), a particularly complicated

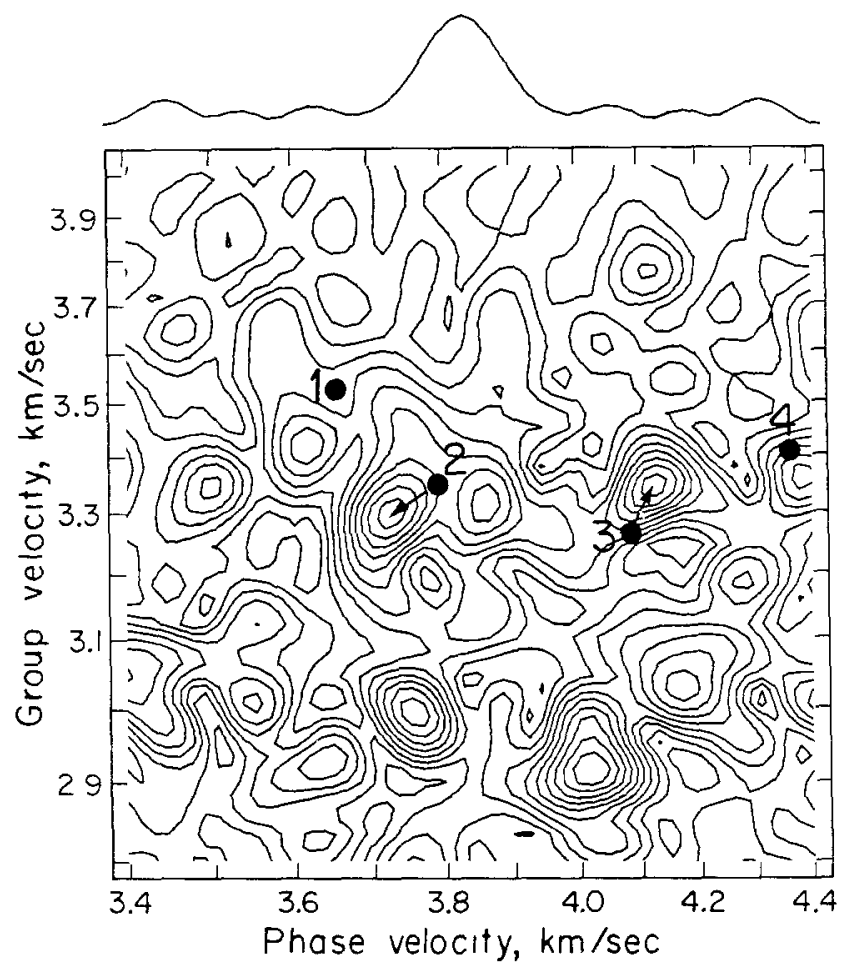

FIG 10 Same as Figure 9 but for profile 1.

pattern emerged on UC diagrams for $U \leqq 3.5 \mathrm{~km} / \mathrm{sec}$, but a very low contours level ( $\leqq 10$ per cent) is observed at higher group velocities.

The general character of observed diagrams shows that (1) the "noise" level is suitably low before $L g$ arrivals for the $M_{L} \sim 4.0$ to 4.4 events we have examined on SCARLET, and (2) late arrivals are systematically observed, which cannot be explained in terms of overtones excited at the source and propagating along direct paths. Spurious peaks observed, e.g., in Figures 9 and 10 are thus probably not due to random noise, but to $L g$-type signals propagating through a laterally varying crust. In particular, peaks observed at $U \leqq 3.2 \mathrm{~km} / \mathrm{sec}$ could be overtones excited by secondary sources, either along the direct path (e.g., mode conversions from $R g$ to overtones at shorter distances), or laterally by reflection off accidents in the crust. Lateral arrivals might play a major role in the case of the Baja California event mentioned above, due to strong lateral variations in the vicinity of the direct path (e.g., Thatcher and Brune, 1973). 
In view of this tentative interpretation, we first focus our attention on the peaks observed between 3.2 and $3.5 \mathrm{~km} / \mathrm{sec}$ on Figures 9 and 10 . Notice that they lie close to the theoretical UC coordinates calculated for the crustal structure used earlier in "Instrumental and Noise Constraints for CEDAR Data." Peaks tentatively identified as modes 1 and 3 on Figure 9, as indicated by the arrows, remain at nearly the same place on Figure 10, although mode 1 is weak in the latter case. On the other hand, poorer stability is observed near the theoretical position for mode 2, and a strong peak emerges on Figure 9 between modes 2 and 3, which requires an explanation. But the first order of business is to follow the peaks tentatively identified on Figures 9 and 10 as functions of period, and thus retrieve experimental dispersion curves for these modes.

We have devised for this purpose an automatic algorithm which retrieves piecewise linear dispersion curves in UTC space from a set of UC diagrams computed at several periods $T$. (In the present case we have $1.8 \leqq T \leqq 5$ sec.) The curves are

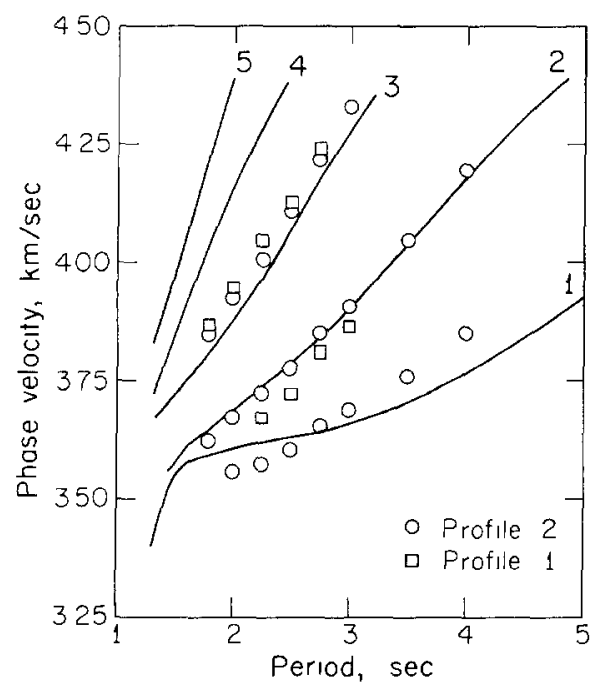

FIG. 11. Phase velocities obtained through the algorithm described in the text for event 1 and profiles 1 and 2 The solid lines are theoretical values computed for the Rayleigh wave model of Hadley and Kanamori (1979).

initially labeled as they pass through peaks identified as overtones at a reference period (e.g., modes 2 and 3 at $2.5 \mathrm{sec}$ on Figure 10). Three criteria are used to follow continuously the peaks from a given period $T$ to a neighboring period $T+\Delta T$, in the form of upper limits allowable on (1) the relative peak amplitude variation $\Delta A / A$, (2) the change in group velocity $\Delta U$, and (3) the departure $\Delta C$ from the predicted phase velocity $C_{p}$ at $T+\Delta T$ from observed phase and group velocities at $T$. More specifically the third criterion assumes that

$$
C_{p}{ }^{-1}(T+\Delta T)=C^{-1}(T)+(\Delta T / T)\left[C^{-1}(T)-U^{-1}(T)\right] .
$$

The search for a continuous curve stops when one or more of these criteria is not met.

Figure 11 depicts phase velocity curves derived from profiles 1 and 2 , with $\Delta A / A$ $\leqq 0.3, \Delta U \leqq 0.1 \mathrm{~km} / \mathrm{sec} \Delta C \leqq 0.1 \mathrm{~km} / \mathrm{sec}$; the period spacing varied from 0.2 to 0.5 sec between 1.8 and $5 \mathrm{sec}$. Also shown on this figure are theoretical curves calculated from the Rayleigh wave model of Hadley and Kanamori (1979) for the western Mojave and the central and eastern Transverse Ranges. This model was chosen in 
this study because it explains the Rayleigh waves at longer periods, it is slightly different from the one used previously, in that it includes a mid-crustal low-velocity zone near $15-\mathrm{km}$ depth. This is the cause of the proximity of modes 1 and 2 near 1.5 sec. (Differences between dispersion curves for the two models affect mainly periods shorter than 2 sec.)

The closeness of these experimental overtone phase velocity curves to the theoretical curves for crustal models derived from independent geophysical dataincluding fundamental Rayleigh mode observations-gives us some confidence that the method is capable of retrieving spatially averaged phase velocity curves from $L g$ records. On the other hand, it should not be forgotten that only a few observed peaks are associated with these curves, even when only the "first Lg arrivals," with the highest group velocities, are considered. Thus, the significance of phase velocity curves such as those shown on Figure 11 must be assessed carefully before they are used to constrain crustal models.

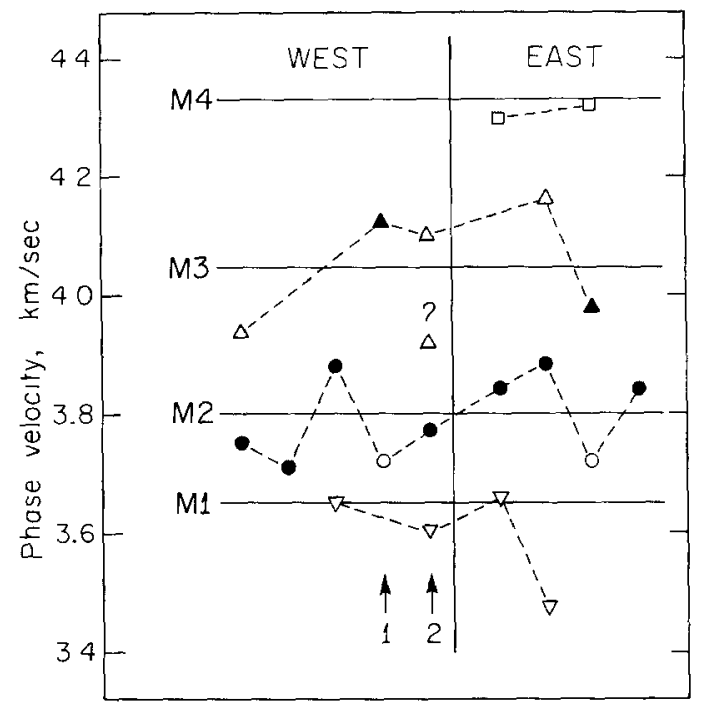

Fig 12 Phase velocities of the first three highest peaks on 2.5-sec period UC diagrams $(U>32 \mathrm{~km} /$ $\mathrm{sec}$ ) for nine profiles running east and west of the Salton Trough (profiles 1 and 2 are indicated by arrows) Dotted lines join the points assumed to belong to the same mode. Full symbols identify highest peak for each profile. For profile 2, the fourth peak is also shown because the thrd peak (marked "?") is not identified as a mode on Figure 9 . Horizontal lines are theoretical values given in Table 2.

\section{Stability of Observations in Southern California}

In addition to profiles 1 and 2 for event 1 , events 2 to 4 (Table 1) have been processed along profiles similar to profile 1 (Figure $2 \mathrm{~b}$ ). This gives us an opportunity to check the stability of phase velocity estimates such as those shown on Figure 11. Events 5 to 7 have been processed along profiles running from CLC, toward the vicinity of Yuma, southeast of the Salton Trough (Figure 2a). All profiles avoid the Salton Trough, where crustal thinning and anomalous mantle structure is expected (e.g., Savino et al., 1977; Fuis et al., 1980). But the latter profiles are different enough to allow us to look for possible lateral variations. Phase velocities at $2.5 \mathrm{sec}$ from these nine profiles are shown in Figure 12, where only the first three highest peaks are shown, except for profile 2 (event 1) for which the fourth highest peak is also shown. Furthermore, peaks with a group velocity smaller than $3.2 \mathrm{~km} / \mathrm{sec}$ are assumed to represent secondary arrivals and are not shown. Phase velocities tentatively assigned to the same mode are linked by dashed lines on Figure 12 (peak 
closest to theoretical mode coordinates in the UC plane), and the highest peak is singled out in each case.

At 2.5-sec period, the highest peak can thus be generally associated with the second overtone, and observed values scattered over less than $0.2 \mathrm{~km} / \mathrm{sec}$ for this mode. Although this is very comparable to the scatter for fundamental Rayleigh wave phase velocities found by Hadley and Kanamori (1979) between 15 and 25 sec, the present situation is actually very different because of the mode identification procedure we have used (the observed maximum scatter being in fact of the same order of magnitude as the theoretical phase velocity spacing between overtones).

TABLE 2

Average Velocities $\bar{c}=\sum_{i=1}^{n} c_{i} / n$ (KM/Sec) Obtained at Different Periods $T$ (Sec) from the Algorithm Described in "Experimental Results." The Same Mode Identification as in Figure 12 is Assumed, with the Exception of the Dot Marked (?) in This Figure Which is Here Assumed to Belong to Mode 3 All the Data Used in This Table at 2.5-Sec Period Belong Thus to the First Three Highest Peaks of UC Diagrams. $c_{t}$ Are the Theoretical Values for the Model Derived in Part I From Kanamori and Hadley (1975)

\begin{tabular}{|c|c|c|c|c|c|c|}
\hline Mode & $T$ & $n$ & $\bar{c}$ & $c_{t}$ & $\bar{c}-c_{t}$ & $\left(\frac{\sum_{l=1}^{n}\left(c_{t}-\bar{c}\right)^{2}}{(n-1)}\right)^{1,2}$ \\
\hline \multirow[t]{8}{*}{1} & 180 & 3 & 3.513 & 3617 & -0.104 & 0.063 \\
\hline & 2.00 & 4 & 3535 & 3626 & -0091 & 0064 \\
\hline & 2.25 & 4 & 3.560 & 3638 & -0.078 & 0.084 \\
\hline & 250 & 4 & 3597 & 3.650 & -0.053 & 0.090 \\
\hline & 2.75 & 4 & 3.635 & 3.665 & -0030 & 0.101 \\
\hline & 3.00 & 4 & 3677 & 3681 & -0004 & 0.097 \\
\hline & 3.50 & 4 & 3742 & 3721 & 0021 & 0113 \\
\hline & 400 & 2 & 3.845 & 3770 & 0.075 & 0.007 \\
\hline \multirow[t]{8}{*}{2} & 180 & 7 & 3.630 & 3683 & -0053 & 0036 \\
\hline & 2.00 & 6 & 3673 & 3713 & -0.040 & 0045 \\
\hline & 225 & 9 & 3731 & 3754 & -0.023 & 0.055 \\
\hline & 250 & 9 & 3761 & 3802 & -0041 & 0059 \\
\hline & 2.75 & 9 & 3.849 & 3857 & -0.008 & 0.070 \\
\hline & 3.00 & 8 & 3915 & 3917 & -0.002 & 0.072 \\
\hline & 350 & 6 & 4048 & 4.049 & -0001 & 0.104 \\
\hline & 4.00 & 5 & 4.188 & 4.180 & 0.008 & 0128 \\
\hline \multirow[t]{7}{*}{3} & 180 & 4 & 3.820 & 3810 & 0010 & 0.107 \\
\hline & 200 & 5 & 3.886 & 3869 & 0017 & 0.134 \\
\hline & 225 & 5 & 3.966 & 3953 & 0.013 & 0.153 \\
\hline & 250 & 5 & 4.062 & 4045 & 0017 & 0166 \\
\hline & 275 & 3 & 4.093 & 4.143 & -0050 & 0.147 \\
\hline & 300 & 2 & 4090 & 4.238 & -0148 & 0.042 \\
\hline & 3.50 & 2 & 4.275 & 4.449 & -0.174 & 0.035 \\
\hline \multirow[t]{4}{*}{4} & 1.80 & 2 & 3.990 & 3987 & 0.030 & 0014 \\
\hline & 200 & 2 & 4.070 & 4080 & -0.010 & 0.014 \\
\hline & 225 & 2 & 4.190 & 4207 & -0.017 & 0.000 \\
\hline & 250 & 2 & 4.340 & 4.333 & 0007 & 0.014 \\
\hline
\end{tabular}

This stability test has been extended to other periods by continuously following the peaks as indicated in "Experimental Results." The standard deviations of observed phase velocities are generally greater for overtones 1 to 3 , in the period range 2 to $4 \mathrm{sec}$, than the differences with theoretical values predicted by the model derived from Kanamori and Hadley (1975) (Table 2), so that interpretation of those measurements in terms of details in the crustal structure would constitute a rather hazardous extension of this work, probably unwarranted at this point. 
The stability test we have just described shows that lateral inhomogeneities probably play a major role, not only where late arrivals are concerned, but also in the interpretation of early peaks as overtones. Based on the results of "Instrumental and Noise Constraints for CEDAR Data," an explanation of the observed instabilities in terms of seismic noise can be rejected. On the other hand, because station distribution varies from profile to profile--even within each of the two groups "east" and "west" shown in Figure 12-reproducibility of propagation characteristics of $L g$ observed along these different sets of stations is not guaranteed. Further complications can arise from different source excitation of the modes for the seven events used (Table 1).

Lateral heterogeneities in the first portion of the paths, together with different amplitude and phase radiation patterns at the source can result in apparently incoherent phase propagation along profiles with nonzero azimuthal aperture, such as those on Figure $2 \mathrm{~b}$. Intra-array structural variations of any kind can also contribute to the scatter on Figure 12, because the profiles sample the area in different ways. Irrespective of their actual cause, phase perturbations might be construed as resulting from a combination of the two extreme types (random and coherent) used in Part 1 for a numerical experiment. Random phase perturbations (statistically independent from station to station) could be due, e.g., to small scale intra-array lateral inhomogeneities with a scale length of $10 \mathrm{~km}$ or less, as in the case of LASA (Aki, 1973; Capon, 1974). Coherent phase velocity variations over a portion of the profile, or azimuthal variations between source and closest station could result in a coherent perturbation over a subgroup of stations.

In the light of the phase perturbation experiment conducted in Part 1, instabilities in the measurements noted on Figure 12 could clearly be accounted for in this fashion. However, the fact that rather consistent results are nevertheless obtained from SCARLET data shows that we are operating close to or within the conditions of applicability of the method (i.e., 1- to 2-sec random fluctuations and 5 per cent phase velocity variations along significant portions of the profiles). Thus better results and greater success can be expected from similar arrays located on a homogeneous crust.

\section{Further Experimental Results: The Northwestern Margin of the Sierra Nevada}

In contrast to the southern California profiles (Figure 2b), two longitudinal profiles along the Sierra Nevada (Figure 13) lie entirely within the same geological province. We might, therefore, anticipate that fewer difficulties linked to lateral variations should be encountered in the latter case, especially if the source is also within the Sierra block (e.g., $S 1$ on Figure 13).

The crustal structure of the Sierra Nevada has been studied by seismic refraction. Using chemical explosions near San Francisco, California, and Eureka, Nevada, Eaton (1963) found evidence of crustal thickening from $20 \mathrm{~km}$ under the Coast Ranges and the Great Valley to about $50 \mathrm{~km}$ under the High Sierra. Crustal thickness drops again to about $30 \mathrm{~km}$ in the Basin and Range (Bateman and Eaton, 1967), indicating that the crustal root is centered approximately beneath the Sierra Crest. Based on an unreversed profile between the Nevada Test Site and San Francisco Bay, Carder et al. (1970) proposed a model with no crustal thickening under most of the western Sierra, and a maximum crustal thickness of about $40 \mathrm{~km}$ beneath Owens Valley and the White Mountains, east of the Sierra front. Upon reanalysis of the San Francisco-Eureka profile, together with other profiles in the southwestern United States, Prodehl (1970) suggested a maximum Moho depth of 
$42 \mathrm{~km}$ beneath the Sierra crest and Owens Valley. Crustal thinning is progressive to the west, to a thickness of about $28 \mathrm{~km}$ near the eastern margin of the Great Valley. Note that gravity data also tend to support an offset of the crustal root to the east of the Sierra block, with a minimum Bouguer anomaly of $-250 \mathrm{mgal}$ in the northern part of Owens Valley (Prodehl, 1970).

The main point of interest to us is that structural inhomogeneities seem to be fairly mild along the western margin of the Sierra, where we chose our profile

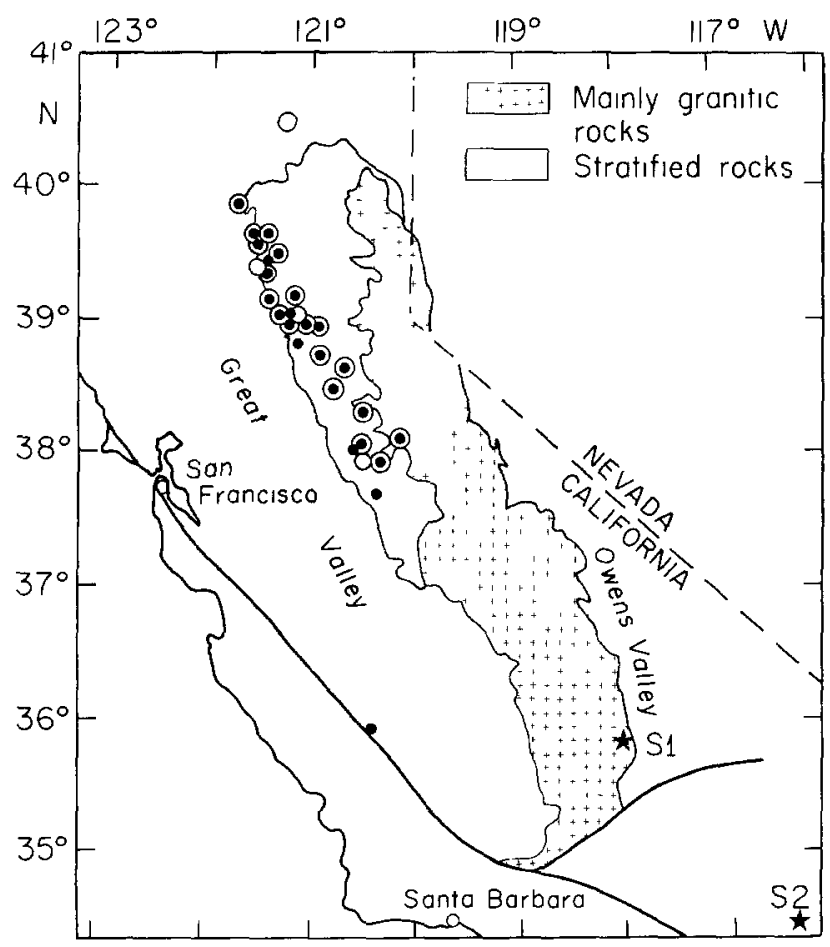

Frg. 13. Simplified geological map showing Sierra Nevada profiles. Stations used in connection with source $S 1$ (S2) are shown by solid (open) circles. (Map after Bateman and Eaton, 1967)

TABLE 3

Events S1 and S2 Used in "Further Experimental Results" Source Parameters Are From JERry Eaton (PERSONal Communication)

\begin{tabular}{ccccccc}
\hline Event & \multicolumn{1}{c}{ Date } & \multicolumn{1}{c}{$H_{11}$} & Lat $(\mathrm{N})$ & Long $(\mathrm{W})$ & $h(\mathrm{~km})$ & $M$ \\
\hline$S 1$ & 14 June 1979 & $7 \mathrm{~h} 39 \mathrm{~m} 2785 \mathrm{~s}$ & $35^{\circ} 4480$ & $118^{\circ} 0030$ & 7.4 & 4.5 \\
$S 2$ & 15 March 1979 & $23 \mathrm{~h} 07 \mathrm{~m} 5811 \mathrm{~s}$ & $34^{\circ} 1969$ & $116^{\circ} 26.33$ & 3.3 & 48 \\
\hline
\end{tabular}

(Figure 13), as most structural variations appear to lie to the east of this profile. It seems therefore justifiable to apply the UC diagram analysis in this case.

We analyzed $L g$ records from two events, labeled $S 1$ and $S 2$ on Figure 13 and Table 3. The profile for event $S 1$ is shown on Figure 14 (after deconvolution) and the corresponding UC diagram at 2.5-sec period is displayed on Figure 15. This diagram exhibits the same fundamental characteristics which were found for southern California profiles. Contour levels are low for group velocities larger than 3.5 $\mathrm{km} / \mathrm{sec}$, and some late energy remains for group velocities slower than $3.2 \mathrm{~km} / \mathrm{sec}$, 
although much less than in the case of southern California profiles. We tentatively identify the clear peaks labeled $\mathrm{A}$ and $\mathrm{B}$ on Figure 15 with the second and third overtones, and the third strong peak (C) with the first overtone, in spite of its lowgroup velocity. Much the same patterns were found for event $S 2$, although the $S / N$
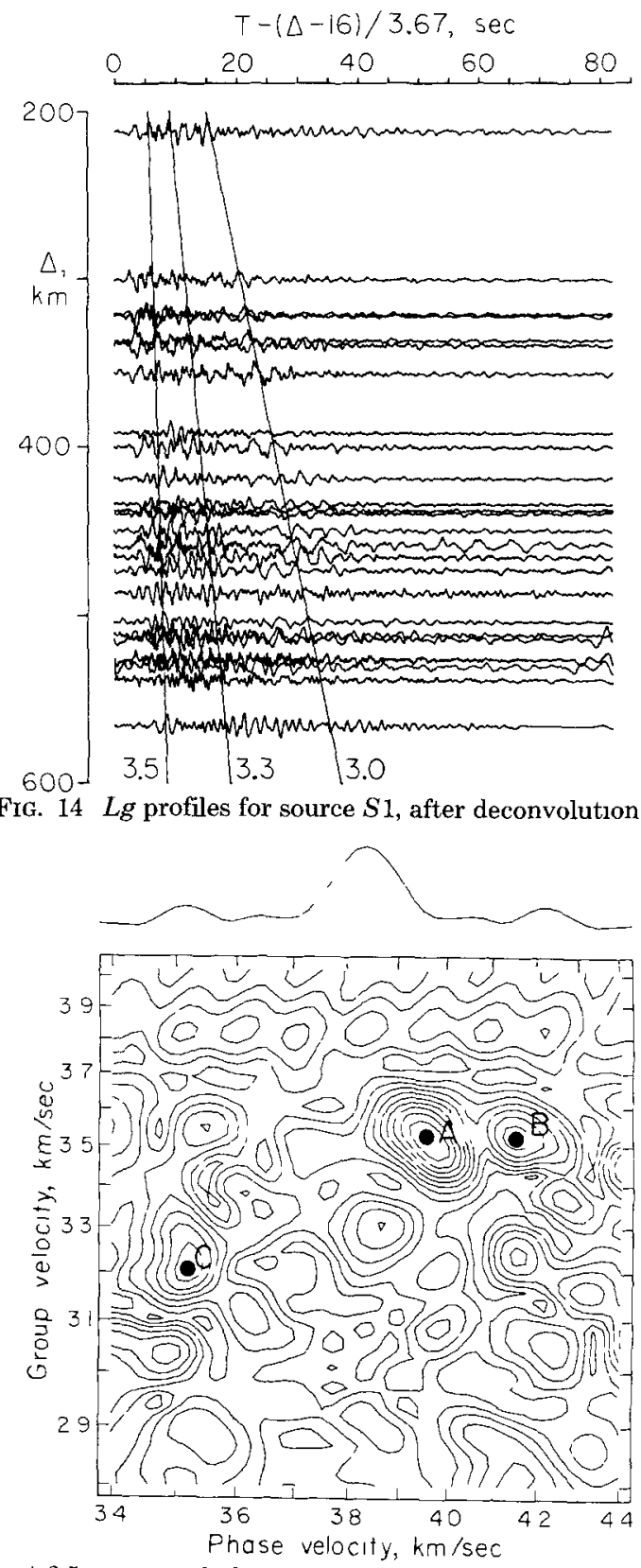

FIG. 15 UC diagram at 25 -sec period obtained from profile shown on Figure 14 Same conventions as Figure 3. A to $\mathrm{C}$ represent highest peaks on diagram

ratio was not quite as favorable, and peaks were consequently not so clear (note also that the path for $S 2$ crosses the Garlock fault, and includes a portion of the Mojave block in addition to the Sierra block, and is, therefore, not as simple as the path for S1). 
By following these peaks as functions of period using the criteria described earlier, we find the experimental dispersion curves shown on Figure 16. The results from sources $S 1$ and $S 2$ are reasonably consistent with each other, and quite different from the experimental results obtained earlier for southern California (Figure 16). Thus, should our interpretation be correct, the overtone dispersion data confirm the large differences between the crustal model of Hadley and Kanamori (1979) for southern California (Figure 11) and a model for the Sierra Nevada derived from the $P$-wave model of Carder et al. (1970) using 1.78 for the ratio of $P$ on $S$ velocity. The latter model provides a fairly good fit to the observed dispersion of overtones 2 and 3 , but the predicted phase velocity for the first overtone is too high at the shorter periods. This can be remedied in part by introducing a low-velocity superficial layer, as shown on the figure. Such a layer might be found indeed along our profile in the form of metavolcanic rocks, although our scanty data set hardly constitutes definitive evidence in favor of such an interpretation. Nevertheless, we regard the internal

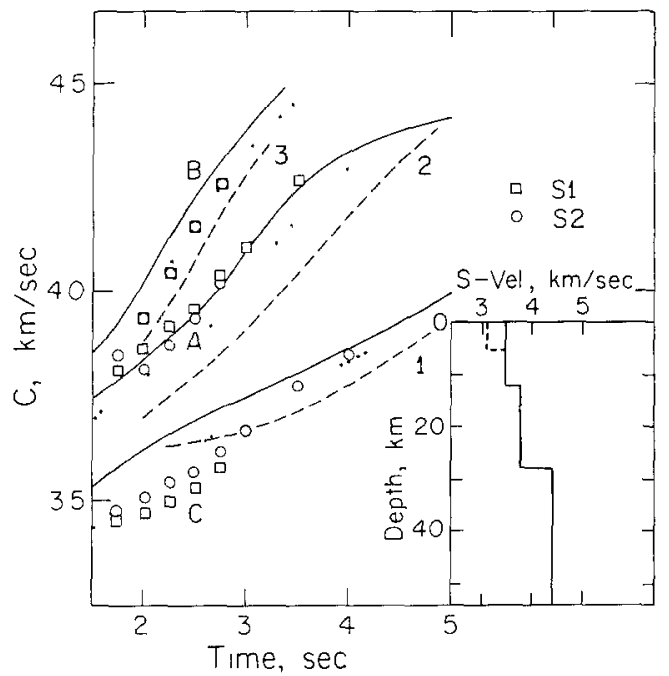

Fig 16 Experimental dispersion curves for Sierra Nevada profiles. Also shown are theoretical dispersion curves for the crustal models shown in inset Solid lines derived from Carder et al. (1970), dashed lines from Hadley and Kanamorl (1979), and dotted lines indicate effect of low-velocity surface layer

consistency of our observations, as well as the clear differences between two geographical regions known to have different crustal structures as encouraging indications that the method yields physically meaningful measurements, and deserves more extensive and systematic applications.

\section{Conclusions}

Application of the UC diagram technique to $L g$ phases recorded on the SCARLET network in southern California and the CALNET network along the northwestern margin of the Sierra block yields in both cases a clear image of the time-frequencywavenumber content of the signal, with spatial resolution of several hundred kilometers.

Gross features of observed UC diagrams show that a representation of $L g$ as a coherent single multi-mode wave train propagating across southern California is an oversimplified view even at rather low frequencies. For example, realistic crustal models for the area do not predict the peaks observed at group velocities smaller 
than $3.2 \mathrm{~km} / \mathrm{sec}$ at 2.5 -sec period. Such peaks can be due either to secondary overtone excitation along the direct path or to lateral reflections and refractions. On the other hand, strong peaks found at group velocities between 3.2 and $3.5 \mathrm{~km} / \mathrm{sec}$ can generally be interpreted as direct arrivals of overtones excited at the epicenter and propagating through a structure which is a spatial average for the area. Instabilities of phase velocity estimates for several events and profiles with a prtort similar structures show however that lateral heterogeneities also play probably a major role for the peaks identified with overtones on UC diagrams in southern California.

A somewhat simpler pattern emerges on UC diagrams for $L g$ phases propagating along the Sierra batholith. Specifically, at 2.5 -sec periods, no strong peak is observed for group velocities slower than $3.2 \mathrm{~km} / \mathrm{sec}$. Peaks found between 3.2 and $3.5 \mathrm{~km} /$ sec can be tentatively identified with overtones, but only two sets of records have been processed and it is difficult to place confidence limits on these observations.

Perhaps the most important observation is that, in spite of slight instabilities, UC diagrams from either SCARLET/CEDAR data or CALNET data exhibit rather consistent patterns in the group velocity window 3.2 to $3.5 \mathrm{~km} / \mathrm{sec}$. We concluded in Part 1 that the method is stable against random phase fluctuations not exceeding half a cycle, or coherent phase velocity variations below the resolution threshold of the array. The results of the present paper strongly suggest that these conditions are nearly, if not clearly, satisfied for the $L g$ records processed in this study. This opens the possibility of using this technique for structural studies by inversion of overtone dispersion curves, particularly in regions with at most weak lateral variations.

\section{ACKNOWLEDGMENTS}

We thank the staff of the Seismological Laboratory and C. Johnson for considerable help in manipulating CEDAR data. D. G Harkrider kındly provided computer programs to compute synthetics G. Eaton and G. Poupinet were very helpful in selecting and digitizing CALNET data This research was supported by the U.S. Geological Survey under Contracts 14-08-0001-18331 and 14-08-0001-19270 and the Advanced Research Projects Agency of the Department of Defense, and was monitored by the Arr Force Office of Scientific Research under Contracts F49620-77-C-0022 and F49620-81-C-0008. M. Cara was supported by a CNRS-NSF fellowshıp (French-U S convention)

\section{REFERENCES}

Ak1, K. (1973). Scattering of $P$ waves under the Montana Lasa, $J$ Geophys Res 78, 1334-1346.

Allen, C. R , P. St. Amand, C. F Richter, and J. M. Nordquist (1965) Relationship between seismicity and geological structure in the southern California region, Bull Selsm Soc Am 65, 753-797

Archambeau, C (1979) Earthquakes hazards determmations based on tectonic stress measurements, Technical Report \#3, USGS Contract No 14-08-0001-16773

Bateman, P. C and J P Eaton (1967). Sierra Nevada batholith, Sclence 158, 1407-1417.

Båth, M. (1956) A continental channel wave, guided by the intermediate layer in the crust, Geofis. Pura Appl. 38, 19-31.

Capon, J. (1974). Characterization of crust and upper mantle structure under LASA as a random medium, Bull. Selsm Soc Am 64, 235-266

Cara, M. and J. B. Minster (1981) Multi-mode analysis of Rayleigh-type Lg Part 1. Theory and applicability of the method, Bull. Seusm. Soc Am 71, 973-984.

Carder, D. S, A Qamar, and T V McEvilly (1970). Trans-California seismic profile-Pahute Mesa to San Francisco Bay, Bull. Setsm. Soc Am 60, 1829-1846.

Eaton, J. P (1963) Crustal structure from San Francisco, Calıforma, to Eureka, Nevada, from selsmic refraction measurements, $J$ Geophys Res. 68, 5789-5806

Fuss, G. S, W D. Mooney, J H Healy, G. A. McMechan, and W. J Lutter (1980) Crustal structure of the Imperial Valley region (in press).

Gutenberg, B. (1955) Channel waves in the Earth's crust, Geophysics 20, 283-294 
Hadley, D and H Kanamor (1979) Regional $S$-wave structure for southern Calıfornı from the analysis of teleseismic Rayleigh waves, Geophys $J$ 58, 655-666.

Hileman, J. A., C. R. Allen, and J. M Nordquist (1973) Selsmicity of the southern Calffornia region, 1 January 1932 to 31 December 1972, Se1smological Laboratory, Calıfornı Instrtute of Technology, Pasadena, Californı

Hutton, K L, C R Allen, A. C Blanchard, S A Fisher, P T. German, D D. Given, C E Johnson, V D Lamanuzzı, B A Reed, K J Richter, and J. H Whitcomb (1979). Southern California array for research on local earthquakes and teleseisms (SCARLET), Caltech-USGS monthly prelımmary epıcenters, Selsmological Laboratory, Calıfornı Institute of Technology, Pasadena, Calıfornıa

Johnson, C. D (1979). CEDAR. an approach to the computer automation of short-period local seismic networks, $P h$ D. Thesis, Seismological Laboratory, Calıfornıa Institute of Technology, Pasadena, Calıfornia

Kanamori, H. and D Hadley (1975). Crustal structure and temporal velocity change in southern California, Pageoph 113, 257-280.

Kanamorı, H, J B. Minster, and K McNally (1979). Selsmological research related to earthquake prediction and hazard reduction, final report, USGS Contract No 14-08-0001-17631

Press, F (1956) Velocity of $L g$ waves in Californa, Trans Am. Geophys. Union 37, 615-618

Prodehl, C. (1970) Seismic refraction study of crustal structure in the Western United States, Bull. Geol. Soc. Am 81, 2629-2645

Savıno, J. M , W L. Rodı, R C. Goff, T. H. Jordan, J. H Alexander, and D. G Lambert (1977). Inversion of combined geophysical data for determination of structure beneath the Imperial Valley geothermal region, Systems, Science and Software, Inc., Report SSS-R-78-3412

Thatcher, W. and J. Brune (1973) Surface waves and crustal structure in the Gulf of Califorma region, Bull. Seusm. Soc Am 64, 235-266

\author{
SEISMOLOGICAL Laboratory \\ California Institute of Technology \\ Pasadena, California 91125 \\ Contribution No. 3476
}

Manuscript recesved July 16, 1980 